\title{
Clinical Data on Transitory Teriparatide-related Hypercalcemia in Daily Practice Treatment for Severe Menopausal Osteoporosis
}

\author{
EDWIN SEVER BECHIR ${ }^{1,}$ MIHAELA JANA TUCULINA* , MARA CARSOTE², MARILENA BATAIOSU², MIHAELA RAESCU4, \\ CRISTIAN NIKY CUMPATA ${ }^{4}$ \\ ${ }^{1}$ Medicine, Pharmacy, Science and Technology University of Tirgu Mures, Faculty of Dental Medicine, 38 Gheorghe Marinescu Str., \\ 540142, Tirgu Mures, Romania \\ 2 Medicine and Pharmacy University of Craiova, Faculty of Dental Medicine, 2-4 Petru Rares Str., 200349, Craiova, Romania \\ ${ }^{3}$ Carol Davila University of Medicine and Pharmacy, C.I. Parhon National Institute of Endocrinology, 34-38 Aviatorilor Av., Bucharest, \\ Romania \\ ${ }^{4}$ Titu Maiorescu University of Bucharest, Faculty of Dental Medicine, 67A Gheorghe Petrascu Str., 031593, Bucharest, Romania
}

\begin{abstract}
Teriparatide (TPT) (C181H291N55051S2) represents a recombinantmolecule acting as human osteoanabolic agent. Transitory hypercalcemia (TH) has been reported in osteoporotic patients treated with daily TPT. Our purpose is to analyze the biochemical features as well as clinical risk factors for fractures in patients with severe osteoporosis treated with TPT who developed TH during first 12 months. This is an observational reallife study. In patients with TH biochemical blood markers like osteocalcin, CrossLaps and P1NP assessed at one year have statistically significant higher values than in subjects associating serum calcium within normal limits under the drug.
\end{abstract}

Keywords: calcium, hypercalcemia, teriparatide, osteoporosis, menopause

Teriparatide $\left(\mathrm{C}_{181} \mathrm{H}_{201} \mathrm{~N}_{55} \mathrm{O}_{51} \mathrm{~S}_{2}\right)$ represents a recombinant molecule having a molecular mass of $4117.72 \mathrm{~g} / \mathrm{mol}$ acting as human osteoanabolic agent if daily administered for up to two years [1-3]. The efficacy is particularly on vertebral fracture risk reduction and some of the non-vertebral osteoporotic sites [4-6]. The bone promoting medicine has a hepatic metabolism through proteolysis and it requires subcutaneous self-administration every day for 18 months or 24 months depending on protocol $[1,7,8]$. When itcomes to assessment of bone parameters under teriparatide (TPT), an expected anabolic window of blood or urinary bone turnover markers is found in addition to bone mineral density (BMD) increase as detected by central DXA (DualEnergy X-Ray Absorptiometry) since DXA remains the golden standard in daily practice for osteoporosis assays [9-11]. Transitory hypercalcemia has been reported in osteoporotic patients treated with TPT [12].

Our purpose is to analyse the biochemical features as well as clinical risk factors of osteoporotic fractures in patients with severe osteoporosis treated with TPT who developed transitory hypercalcemia.

\section{Experimental part}

Material and method

This a real-life observational study based on menopausal women. Transversal and longitudinal elements of the study are provided. The follow-up period includes 12 months of 24 as intended for TPT therapy (self-subcutaneous administration of $20 \mu \mathrm{g} /$ day).

Figure 1 introduces the study protocol in relationship to TPT administration.

\section{Inclusion criteria}

Included subjects had the criteria for TPT therapy based on Romanian protocol of free reimbursement. Severe menopausal osteoporosis meaning at least one prevalent fragility fracture in association with a low T-score at central DXA is necessary. Also, the patients signed their consent for using their medical records. The group with hypercalcemia is considered in patients to whom an abnormal value of total/ionic serum calcium was found

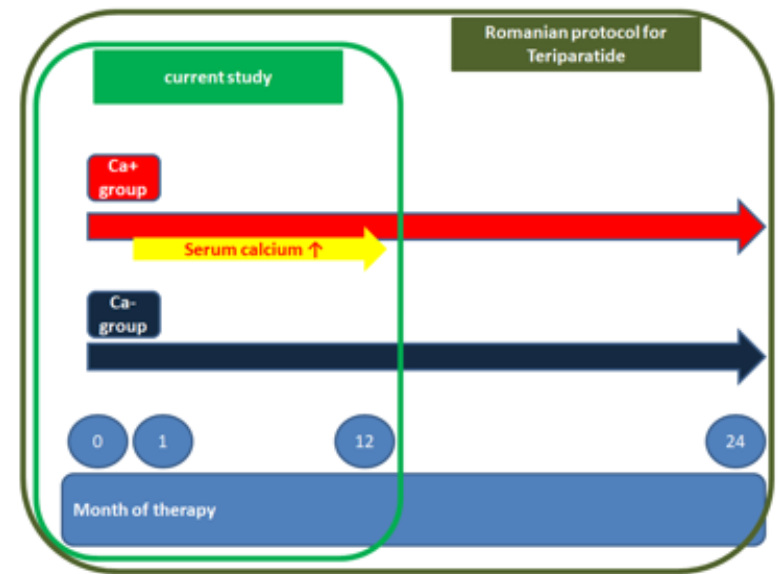

Fig. 1. The chart of study design: Out of 24 months, the first 12 months of therapy with daily teriparatide were analysed based on transitory hypercalcemia

after TPT was started at any moment during first 12 months of therapy except initial evaluation. For this study we only included female patients (despite the fact that the country protocol allows TPT therapy in males with severe hypogonadism- and glucocorticoid- related osteoporosis) $[13,14]$

Exclusion criteria: We used the general contraindications of TPT. TPT is commonly contraindicated in primary and secondary bone malignancies, prior or current radiotherapy, hypercalcemia of any cause, hyperparathyroidism, and bone metabolic disorders like Paget's disease. Particularly, we did not included patients with suspected or confirmed malignancies of any type, regardless skeleton involvement.

The assessment: The subjects were evaluated by their current clinician (endocrine specialist). The fracture risk is detected based on anamnesis including prior conditions, previous hip fractures at parents, corticoid exposure, but also based on body mass index, chemical assays (total and ionic calcium, phosphorus, 25-hydroxyvitamin D, parathormon, osteocalcin, CrossLaps, P1NP) and DXA assay (lumbar, total hip and femoral neck regions). DXA results were provided as BMD and T-score. Blood bone 
hormones as 25-hydroxyvitamin D (a pro-hormone) and circulating intact parathormone (PTH). Blood bone turnover markers are for formation: alkaline phosphatase, osteocalcin, P1NP and for resorption: CrossLaps. Also we included baseline evaluation of 24-hours urinary calcium (which is not part of mandatory profile at TPT initiation according to country specific protocol). All the patients had also thyroid profile assessed based on Thyroid Stimulating Hormone (TSH), and freeT4 (levothyroxine), and Glucocorticoid axes based on morning plasma ACTH (Adrenocorticotropic Hormone), and plasma cortisol. Statistical significance cut off was $p<0.05$.

\section{Results and discussions}

Clinical parameters at TPT initiation: Studied population $(\mathrm{N}=24)$ included patients who developed transitory hypercalcemia (group $\mathrm{Ca}+, \mathrm{N}=4$ ) and subjects without this side effect during follow-up period of time (group Ca, $N=18$ ). No statistical significance difference was found between the groups regarding the age when TPT treatment was initiated, the period of time since last menstruation (according to menopausal status), and body mass index (BMI) (table 1).

Of all patients, only $11 \%$ of Ca- group were current smokers. Half of the persons in each group had prior upper digestive conditions. One patient in Ca- group had diabetes mellitus and none in $\mathrm{Ca}+$ group. In both groups, current exposure to corticotherapy was found in $11 \%$ of subjects from Ca- group. None of the patients who developed hypercalcemia associated a thyroid condition. 2 out of 4 females had rheumatoid arthritis. $22 \%$ of $\mathrm{Ca}+$ group patients had intolerance to oral bisphosphonates and none of Ca- group. Except from one case in $\mathrm{Ca}+$ group and 3 cases in Ca- group, all subjects had prevalent vertebral fractures (at least one vertebra was involved) of lowtrauma/spontaneous type. Despite a statistical tendency, the years of prior exposure to specific anti-osteoporotic therapy (mostly bisphosphonates) was of median 6 , respective 3 years (table 2).

Chemical parameters at TPT initiation: The analysis of chemical parameters at TPT start showed similar values of blood assays for ionic/total calcium, phosphorus, glycated haemoglobin and also urinary calcium (the measurement for 24 hours) (table 3). The bone, thyroid and adrenal axes evaluation showed similar profile between the groups (table 4). Similar data was showed at baseline according to DXA results using BMD and T-score (table 5).

The parameters after 1 year of daily TPT: DXA results show that regardless the pattern of serum calcium, the BMD and T-score had the same values from a statistical point of view (table 6). Total calcium was statistically significant higher in $\mathrm{Ca}+$ group (table 7). Despite a weak tendency $(p=0.08)$ PTH was not lower in Ca+ patients (Fig. 7). Three out of four blood bone turnover markers were statistically significant higher in $\mathrm{Ca}+$ group (table 7).

Observations related to transitory hypercalcemia: In our cohort, $16.6 \%$ of patients were registered with temporary

\begin{tabular}{|r|r|r|r|}
\hline parameter & age & menopausal period & body mass index \\
\hline average & 71.25 & 25 & 23.5 \\
\hline median & 71 & 22.5 & 24.5 \\
\hline SD & 9.178 & 11.575 & 3.872 \\
\hline min & 62 & 14 & 18 \\
\hline max & 81 & 41 & 27 \\
\hline average & 65.055 & 19.833 & 24.333 \\
\hline median & 67 & 20 & 24 \\
\hline SD & 8.083 & 8.985 & 4.665 \\
\hline min & 47 & 4 & 35 \\
\hline max & 76 & 0.332 & 17 \\
\hline p value & 0.189 & years & 33 \\
\hline Units & years & 0.744 \\
\hline
\end{tabular}

Table 1

THE GROUP WITH HYPERCALCEMIA $(\mathrm{Ca}+)$ IN RED AND WITHOUT (Ca-) IN BLACK; WE INTRODUCE THE AGE, YEARS SINCE MENOPAUSE AND BODY MASSINDEX AT INITIAL

EVALUATION OF PATIENTS REFERRED FOR TERIPARATIDE THERAPY

\begin{tabular}{|r|r|}
\hline & vears of prior therapy \\
\hline average & 6 \\
median & 6 \\
\hline SD & 1.825 \\
\hline min & 4 \\
max & 8 \\
\hline average & 3.444 \\
\hline median & 3 \\
\hline SD & 2.812 \\
\hline min & 0 \\
\hline max & 9 \\
\hline p value & 0.1 \\
\hline
\end{tabular}

\begin{tabular}{|rrrrrrr|}
\hline parameter & ionic calcium & total calcium & urinary calcium & phosphorus & glycated hemoglobin \\
average & 4.173 & 9.633 & 0.175 & 2.903 & 5.835 \\
median & 4.1 & 9.6 & 0.175 & 2.9 & 5.835 \\
SD & 0.2 & 0.251 & 0.049 & 0.095 & 0.134 \\
min & 4.02 & 9.4 & 0.14 & 2.81 & 5.74 \\
max & 4.4 & 9.9 & 0.21 & 3 & 5.93 \\
average & 4.1 & 9.516 & 0.143 & 3.703 & 5.532 \\
median & 4.15 & 9.5 & 0.09 & 3.8 & 5.6 \\
\hline SD & 0.163 & 0.332 & 0.1 & 0.704 & 0.528 \\
min & 3.9 & 9 & 0.03 & 2.3 & 4.8 \\
max & 4.3 & 10.2 & 0.33 & 4.8 & 6.7 \\
\hline p value & 0.527 & 0.572 & 0.683 & 0.073 & 0.453 \\
units & $\mathrm{mg} / \mathrm{dL}$ & $\mathrm{mg} / \mathrm{dL}$ & $\mathrm{g} / 24$-hours urine & $\mathrm{mg} / \mathrm{dl}$ & $\%$ \\
normal & $3.9 \cdots 4.9$ & $8.5 \cdots 10.2$ & $0.07 \cdots 0.3$ & $2.5 \cdots 4.5$ & $4.8 \cdots 5.9$ \\
\hline
\end{tabular}

Table 2

THE YEARS OF PREVIOUS SPECIFIC MEDICATION FOR OSTEOPOROSIS IN EACH GROUP: Ca+ (RED) GROUP, RESPECTIVE Ca- (BLACK) GROUP. ALL THE PATIENTS WERE TREATED WITH DAILY $20 \mu \mathrm{G}$ TERIPARATIDE. 
Table 4

BONE, THYROID AND GLUCOCORTICOID PARAMETERS AT TERIPARATIDE INITIATION: Ca+ GROUP (RED), Ca- GROUP (BLACK)

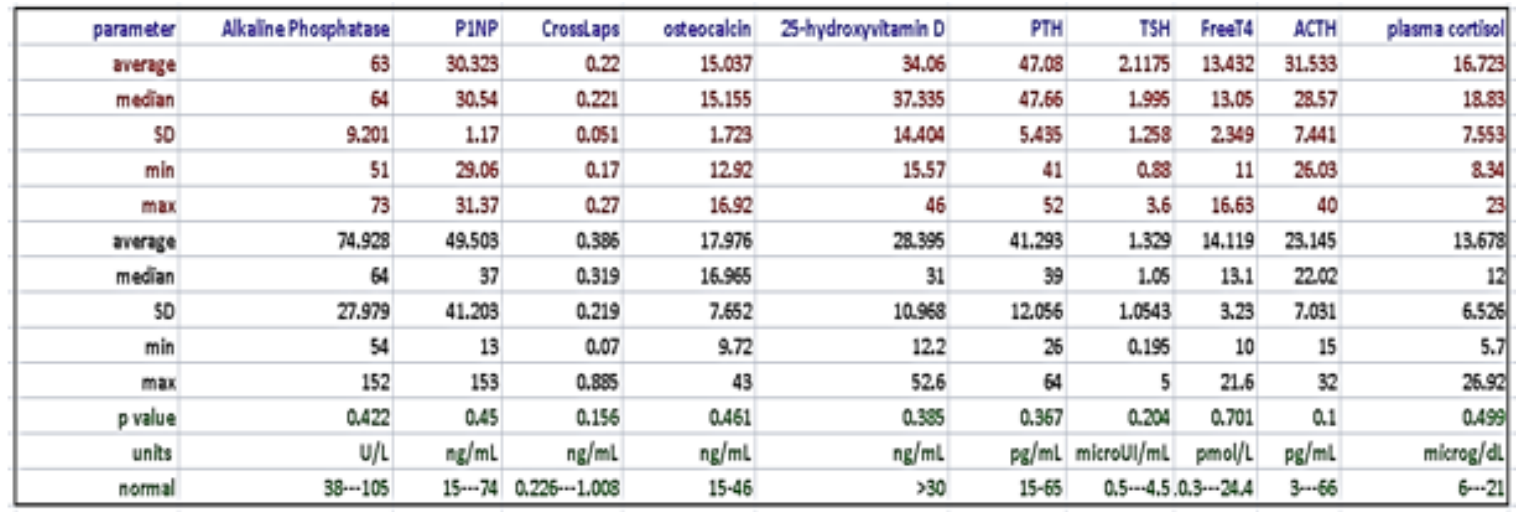

Table 5

CENTRAL DXA (GE LUNAR PRODIGY DEVICE) PARAMETERS AT TERIPARATIDE INITIATION:

Ca+ GROUP (RED), Ca- GROUP (BLACK)

\begin{tabular}{|c|c|c|c|c|c|c|}
\hline \multirow{2}{*}{$\begin{array}{r}\text { parameter } \\
\text { average }\end{array}$} & \multicolumn{2}{|c|}{ lumbar BMD lumbar T-score } & \multicolumn{2}{|c|}{ femoral neck BMD femoral neck T-score } & \multirow{2}{*}{$\begin{array}{r}\text { total hip BMD } \\
0.787 \\
\end{array}$} & \multirow{2}{*}{$\begin{array}{r}\text { total hip BMD } \\
-1.75\end{array}$} \\
\hline & 0.81 & $\cdot 3.125$ & 0.767 & -1.95 & & \\
\hline median & 0.8025 & -3.15 & 0.764 & -1.95 & 0.804 & -1.6 \\
\hline SD & 0.065 & 0.75 & 0.065 & 0.45 & 0.061 & 0.472 \\
\hline $\min$ & 0.731 & -3.9 & 0.691 & -2.5 & 0.705 & -2.4 \\
\hline $\max$ & 0.904 & -2.3 & 0.851 & -1.4 & 0.836 & -1.4 \\
\hline average & 0.788 & -3.229 & 0.721 & -2.225 & 0.75 & -1.962 \\
\hline median & 0.783 & -3.2 & 0.737 & -2.2 & 0.781 & -1.8 \\
\hline SD & 0.079 & 0.661 & 0.087 & 0.701 & 0.108 & 0.898 \\
\hline $\min$ & 0.638 & -4.5 & 0.512 & -3.9 & 0.517 & -3.6 \\
\hline $\max$ & 0.939 & -2.2 & 0.816 & -1.1 & 0.892 & -0.5 \\
\hline$p$ value & 0.643 & 0.784 & 0.347 & 0.47 & 0.525 & 0.657 \\
\hline units & $\mathrm{g} / \mathrm{sqcm}$ & SD & $\mathrm{g} / \mathrm{sqcm}$ & SD & $\mathrm{g} / \mathrm{sqcm}$ & SD \\
\hline
\end{tabular}

Table 6

CENTRAL DXA (GE LUNAR PRODIGY DEVICE) PARAMETERS AFTER ONE YEAR OF DAILY TERIPARATIDE ( $20 \mu \mathrm{g}$, SUBCUTANEOUS, SELF ADMINISTRATION): Ca+ GROUP (RED), Ca- GROUP (BLACK)

\begin{tabular}{|c|c|c|c|c|c|c|}
\hline parameter & lumbar BMD & lumbar $\mathrm{T}$-score & femoral neck BMD & femoral neck T-score & total hip BMD & total hip T-score \\
\hline average & 0.827 & -2.95 & 0.744 & -2.125 & 0.789 & -1.725 \\
\hline median & 0.83 & -2.9 & 0.702 & -2.4 & 0.8 & -1.65 \\
\hline SD & 0.08 & 0.806 & 0.099 & 0.694 & 0.067 & 0.537 \\
\hline $\min$ & 0.736 & -3.9 & 0.682 & -2.6 & 0.703 & -2.4 \\
\hline $\max$ & 0.912 & -2.1 & 0.891 & -1.1 & 0.852 & -1.2 \\
\hline average & 0.869 & -2.57 & 0.753 & -2.025 & 0.779 & -1.812 \\
\hline median & 0.865 & -2.6 & 0.75 & -2.05 & 0.802 & -1.6 \\
\hline SD & 0.101 & 0.878 & 0.08 & 0.579 & 0.111 & 0.913 \\
\hline $\min$ & 0.693 & -4.1 & 0.602 & -3.1 & 0.554 & -3.6 \\
\hline $\max$ & 1.027 & -1.2 & 0.917 & -0.9 & 0.978 & -0.2 \\
\hline $\mathrm{p}$ value & 0.445 & 0.44 & 0.84 & 0.768 & 0.867 & 0.857 \\
\hline Units & $\mathrm{g} / \mathrm{sqcm}$ & SD & $\mathrm{g} / \mathrm{sqcm}$ & SD & $\mathrm{g} / \mathrm{sqcm}$ & SD \\
\hline
\end{tabular}

Table 7

PARAMETERS OF PHOSPHO-CALCIUM AND BONE METABOLISM AFTER ONE YEAR OF DAILY TERIPARATIDE (20 $\mu \mathrm{g}$, SUBCUTANEOUS, SELF ADMINISTRATION): Ca+ GROUP (RED), CA- GROUP (BLACK)

\begin{tabular}{|c|c|c|c|c|c|c|c|c|c|}
\hline parameter & total calcium & ionic calcium & phosphorus & AP & P1NP & $\mathrm{Cl}$ & $O C$ & $25 \mathrm{OHD}$ & PTH \\
\hline average & 10.466 & 4.54 & 3.2 & 111.333 & 221 & 1.543 & 91.99333 & 26.75 & 26.25 \\
\hline median & 10.2 & 4.32 & 3.2 & 127 & 234 & 1.28 & 97 & 26.5 & 22 \\
\hline SD & 1.222 & 0.582 & 0.1 & 33.381 & 71.39328 & 0.953114 & 18.03885 & 7.135592 & 17.51904 \\
\hline $\min$ & 9.4 & 4.1 & 3.1 & 73 & 144 & 0.749 & 71.98 & 19 & 10 \\
\hline $\max$ & 11.8 & 5.2 & 3.3 & 134 & 285 & 2.6 & 107 & 35 & 51 \\
\hline average & 9.541 & 4.435 & 3.75 & 88.941 & 116.1513 & 0.709833 & 51.21833 & 26.37176 & 40.84647 \\
\hline median & 9.6 & 4.2 & 3.7 & 83 & 119.25 & 0.705 & 49.565 & 23 & 42 \\
\hline SD & 0.355 & 1.111 & 0.558 & 25.42506 & 51.84097 & 0.263119 & 23.36238 & 12.6409 & 13.85744 \\
\hline $\min$ & 8.9 & 3.75 & 2.9 & 60 & 49 & 0.343 & 20.69 & 7.41 & 18.92 \\
\hline $\max$ & 10.2 & 8.7 & 4.5 & 163 & 221 & 1.32 & 101 & 51 & 71.36 \\
\hline p value & 0.01 & 0.87 & 0.11 & 0.1 & 0.007 & 0.003 & 0.01 & 0.95 & 0.08 \\
\hline units & $\mathrm{mg} / \mathrm{dl}$ & $\mathrm{mg} / \mathrm{dL}$ & $\mathrm{mg} / \mathrm{dL}$ & $U / L$ & $\mathrm{ng} / \mathrm{mL}$ & $\mathrm{ng} / \mathrm{mL}$ & $\mathrm{ng} / \mathrm{mL}$ & $\mathrm{ng} / \mathrm{mL}$ & $\mathrm{pg} / \mathrm{mL}$ \\
\hline normal & $8.5 \cdots 10.2$ & $3.9--4.9$ & $2.5 \cdots 4.5$ & $38 \cdots 105$ & $15-742$ & $26-\cdots 1.008$ & $15-46$ & $>30$ & $15 \cdot 65$ \\
\hline
\end{tabular}


increase of blood calcium in a drug-related manner, a rate that confirms data from literature [12-15]. In neither of cases with transitory hypercalcemia TPT was not necessary to be stopped. None of the cases included in $\mathrm{Ca}+$ group had signs or symptoms suggestive for hypercalcemia (like nausea, vomiting, slow intestinal transit, muscle asthenia, etc.); this was an incidental lab finding $[13,14]$. The practical approach in each case of high calcium was individualised like adequate water intake was recommended as well as stopping the calcium supplements. Vitamin D supplements were temporary stopped only in one case (for a month). As mentioned at exclusion criteria, at baseline no case of primary hyperparathyroidism was included so transitory calcaemia is PTH-independent (as showed the PTH results after first 12 months of TPT exposure) [16]. A mild increase of PTH above normal limit was registered in one case from $\mathrm{Ca}$ group after 12 months of TPT (of $71.36 \mathrm{pg} / \mathrm{mL}$, normal level between 15 and $65 \mathrm{pg} / \mathrm{mL}$ ) but this was proven to be related to low 25-hydroxyvitamin D level and immediate correction was provided to the patient.

As positive aspect of the current study we mention the fact that a limited number of studies including Romanian protocol of TPT prescription are published online until this moment [10]. TPT is available only based on endocrinologist decision and prescription since 2013-2014 when it was first released the national TPT protocol $[13,14]$. As negative practical points of the study we mention the following: the small number of patients, the need for chemical, DXA, and incident fractures follow-up data between month 13 and 24 of TPT therapy as TPT protocol recommends. Also, the decision of vitamin D and calcium supplements was done on case- based approach so no general pattern of supplementation may be appreciated in patients with TPT. The target of vitamin D supplementation was the normal level of serum circulating 25hydroxyvitamin D levels above $30 \mathrm{ng} / \mathrm{mL}$ while calcium of $500-1000 \mathrm{mg}$ per day was added depending of individual intake during meals. According to national protocol, the serial assays of serum total and ionic calcium are done at baseline, after one year, respective after 2 years of therapy. In the meantime the calcium evaluation is useful but some transitory self-limited cases of hypercalcemia may not be detected if a specific calendar of serum calcium assessment is not similarly performed in each case. Moreover, the timing of blood calcium assay is important since most of TPT-related hypercalcemia cases are described within first 16 hours of administration [12-15]. In our study all included patients were confirmed with hypercalcemia for at least two different assays in two different days.

Based on our observations, except for alkaline phosphatase, the bone turnover markers like osteocalcin, CrossLaps, and P1NP were statistically significant different between the two groups which were similar at baseline regarding blood and DXA bone profile. However, when it comes to one-year analysis, DXA results are not influenced by blood assays. Many bone-derived factors as well as bone targeting molecules, biomarkers and hormones like prolactin, serotonin, sclerostin, etc. are probably related to skeleton profile and most of them are not tested in daily practice in order to evaluate to fracture risk reduction under specific bone forming medication [17-19].

\section{Conclusions}

In patients who developed transitory PTH-independent hypercalcemia during the first 12 months of daily teriparatide for severe osteoporosis, biochemical markers like osteocalcin, CrossLaps and P1NP assessed at one year have statistically significant higher values than in subjects associating serum calcium within normal limits under the drug.

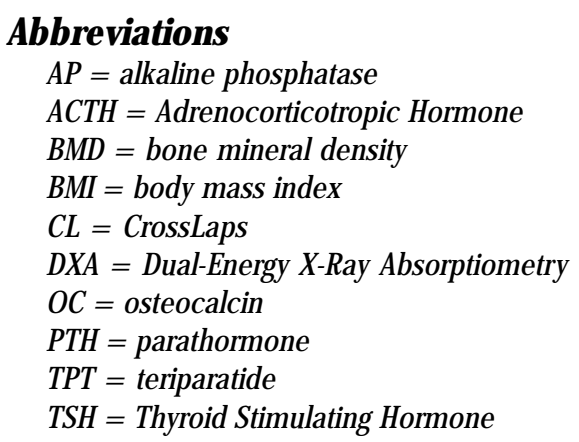

\section{References}

1.*** https://en.wikipedia.org/wiki/Teriparatide

2.TAN, X, WEN, F, YANG, W, XIE, JY, DING, LL, MO, YX, Menopause, 2019, doi: 10.1097/GME.0000000000001321

3.YUAN, F, PENG, W, YANG, C, ZHENG, J, Int J Surg, 66, 2019, p. 1-11 4.RIZZOLLI, R, Best Pract Res Clin Endocrinol Metabol, 32, No. 5, 2018, p. 739-757

5.*** https://www.drugbank.ca/drugs/DB06285

6.FUKUMOTO, S, MATSUMOTO, T, F1000Res, 6, 2017, p. 625

7.COMPSTON, JE, MCCLUNG, MR, LESLIE, WD, Lancet, 393, No. 10169, 2019, p. 364-376

8.LORENTZON, M, J Intern Med, 285, No. 4, 2019, p. 381-394

9.CAMEN, A., CARSOTE, M., VALEA, A., PREDA, S.A., IONOVICI, N., RADU, L., ALBULESCU, D.M., Rev. Chim. (Bucharest), 70, no. 2, 2018, p. $571-574$

10.RADU, L., CARSOTE, M., PREDESCU, A.M., COJAN, T.S., SOCEA, B., BALEANU, V..D., POPESCU, M., IONOVICI, N., ALBULESCU, D.M., ReV. Chim. (Bucharest), 69, no. 12, 2018, p. 3483-3485

11.ABATE, EG, Endocr Pract, 23, No. 6, 2017, p. 745-746

12.*** https://www.accessdata.fda.gov/drugsatfda_docs/label/2008/ 021318s015lbl.pdf

13.*** https://www.ema.europa.eu/en/documents/productinformation/forsteo-epar-product-information_ro.pdf

14.*** https://ec.europa.eu/health/documents/community-register/ 2007/2007062126748/anx 26748 ro.pdf

15.THIRUCHELVAM, N, RANDHĀWA, J, SADIEK, H, KISTANGARI, G, Case Rep Endocrinol, 2014, 2014:802473, doi: 10.1155/204/802473

16.RADU, L, CARSOTE, M, GHEORGHISAN-GALATEANU, AA, PREDA, SA, CALBOREAN, V., STANESCU, R., GHEORMAN, V., ALBULESCU, D.M., Rev. Chim. (Bucharest), 69, no. 10, 2018, p. 2754-2758

17.ALBULESCU, D.M., CARSOTE, M., IONOVICI, N., GHEMIGIAN, A., POPESCU, M., TUCULINA, M.J., DASCALU, I.T., PREDA, S.A., TIRCA, T., PETRESCU, MS, BATAIOSU, M, BECHIR, ES, Rev. Chim. (Bucharest), 69, no. 9, 2018, p. 2438-2442

18.POIANA, C, CHIRITA, C, CARSOTE, M, HORTOPAN, D, GOLDSTEIN, A, Maturitas, 62, no 1, 2009, p. 98-102

19. PARVEEN, B, PARVEEN, A, VOHORA, D, Endocr Metab Immune Disord Drug Targets, 2019, doi: 10.2174/1871530319666190204165207.

Manuscript received: 21.06 .2019 